\title{
Clinical screening of oropharyngeal dysphagia: standard of care
}

\author{
To the Editor:
}

We read with interest the paper by VERIN et al. [1] related to oropharyngeal dysphagia and its importance in institutionalised neurological and head and neck patients, between others. Furthermore, this is a very common problem in the critical and intermediate care settings, and a similar situation occurs with other acute neurological diseases, such as amyotrophic lateral sclerosis, cerebral trauma, post-neurosurgical procedures and toxic metabolic encephalopathies [2, 3]. The authors emphasised the necessity of identifying risks factors for aspiration early and suggested that clinical screening methods are needed to recognise patients with oropharyngeal dysphagia. However, swallowing clinical screening performed by speech therapists and nurses is a standard of care in critical care units. This concept is particularly relevant, considering that in stroke patients, the prognosis is closely related to the medical complications, and aspiration is responsible for $>50 \%$ of these and increases mortality for up to $33 \%$ at 6 months. Even more, after the acute phase of a stroke, swallowing dysfunction has a recovery capacity of $87 \%$ at 6 months [4-6].

Video fluoroscopy, as mentioned by the authors, is the gold standard to demonstrate aspiration. However, is also useful in evaluating tongue movement, velopalatal closing, laryngeal elevation, epiglottic closing and the tone of the cricopharyngeal sphincter. Nevertheless, in acute neurological patients, the interpretation of video fluoroscopy is controversial, and results may not be reliable due to the frequent difficulty of patients to comprehend and collaborate during the test. This may be due to altered consciousness, drugs, and inability to sit and perform an adequate swallowing. Nasolaryngoscopy is a more readily available tool and has been considered the main exam for bedside evaluation. Some evidence suggests performing clinical screening and a nasolaryngoscopy as the first steps for bedside evaluation. Endoscopic criteria of aspiration are flooding of the hypopharynx, flooding of the epiglottic vallecula and piriform pouches, or direct observation of aspiration of secretions or coloured jelly through the glottis $[2,4,6,7]$.

Clinical clues of swallowing deficit can be suspected depending on the affected area of the nervous system. In left cerebral hemisphere disease, patients commonly present with apraxia and deterioration of the oral phase of feeding. In right cerebral hemisphere injuries, patients commonly present with pharyngeal phase alteration with a high risk of aspiration. In stem lesions, severe involvement of the pharyngeal phase is characteristic [5, 6]. In Parkinson's disease, hypertonia of the cricopharyngeal sphincter is common, and in amyotrophic lateral sclerosis, dysphagia is the rule.

A series of simple and cost-effective clinical evaluations are regularly performed by speech therapists, helping to detect patients with a risk of aspiration [6-8] and reduce erroneous decisions regarding initiation of feeds. Common clinical monitoring of aspiration consists of clinical examination of the neck, cranial nerves, laryngeal elevation, velopalatal movement, gag reflex, characteristics of phonation and cough with swallowing [6-8], the three-ounce water test [9], and cervical auscultation [10].

The three-ounce water test is a well-known and useful bedside screening tool [9] with a sensitivity of 84.6$88.23 \%$ and negative predictive value of $81.8-93.75 \%[8,9]$. In patients with stroke, the use of diverse clinical indicators and endoscopic observation of aspiration has a sensitivity of $86 \%$ and a negative predictive value of $73 \%$ [7]. In other series, the association of two abnormal variables indicates a high risk of aspiration: association of wet voice and noisy cervical auscultation has shown a sensitivity of $76.92 \%$, a negative predictive value of $89.65 \%$ and a negative likelihood ratio of 0.24 . The association of the three-ounce swallowing test and wet voice, with a sensitivity of $90 \%$, a negative predictive value of $95.65 \%$ and a negative likelihood ratio of 0.11 , practically exclude dysphagia.

@ERSpublications

The three-ounce water test is a well-known and useful bedside screening tool for oropharyngeal dysphagia http://ow.ly/9Krl30cW2HJ

Cite this article as: Caviedes I, Fernandez-Bussy S, Labarca G, et al. Clinical screening of oropharyngeal dysphagia: standard of care. Eur Respir J 2017; 50: 1701030 [https://doi.org/10.1183/13993003.01030-2017]. 
The rationale in performing screening of oropharyngeal dysphagia is, of course, to protect the airway from aspiration, to reduce the incidence of pneumonia and to define procedures that guarantee a comprehensive nutrition. This clinical screening has an elevated sensitivity and negative predictive value. Clinical and nasolaryngoscopic screening of oropharyngeal dysphagia have also been useful for the critical care team to decide on endoscopic or percutaneous gastrostomy and percutaneous tracheotomy, particularly in patients with a low probability of recovering in the first month after a stroke. It is also useful to make a decision as to whether to suspend oral feeding and indicate rehabilitation by speech therapists [5-7, 9]. This evaluation is usually performed by a multidisciplinary team of pulmonary and ear, nose and throat specialists, together with speech therapists and nurses.

Ivan Caviedes ${ }^{1}$, Sebastian Fernandez-Bussy ${ }^{2}$, Gonzalo Labarca $\circledast^{3,4}$ and Felix J.F. Herth ${ }^{5}$

${ }^{1}$ Servicio y Laboratorio Broncopulmonar, Clínica Alemana de Santiago, Facultad de Medicina, Clínica Alemana, Universidad del Desarrollo, Santiago, Chile. ${ }^{2}$ Servicio de Neumología Intervencionista, Clínica Alemana de Santiago, Facultad de Medicina, Clínica Alemana, Universidad del Desarrollo, Santiago, Chile. ${ }^{3}$ Facultad de Medicina, Universidad San Sebastian, Concepcion, Chile. ${ }^{4}$ Complejo Asistencial Dr Víctor Ríos Ruiz, Los Ángeles, Chile. ${ }^{5}$ Dept of Pneumology and Critical Care Medicine, Thoraxklinik University of Heidelberg, Heidelberg, Germany.

Correspondence: Iván R. Caviedes, Servicio y Laboratorio Broncopulmonar, Clínica Alemana de Santiago. Chile, Facultad de Medicina, Clínica Alemana, Universidad del Desarrollo, Av. Vitacura 5951, Santiago, 6681920, Chile.

E-mail: icaviedes@alemana.cl

Received: May 192017 | Accepted: June 062017

Conflict of interest: None declared

\section{References}

1 Verin E, Clavé P, Bonsignore MR, et al. Oropharyngeal dysphagia: when swallowing disorders meet respiratory diseases. Eur Respir J 2017; 49: 1602530.

2 Leder SB, Cohn SM, Moller BA. Fiberoptic endoscopic documentation of the high incidence of aspiration following extubation in critically ill trauma patients. Dysphagia 1998; 13: 208-212.

3 Schurr MJ, Ebner KA, Maser AL, et al. Formal swallowing evaluation and therapy after traumatic brain injury improves dysphagia outcomes. J Trauma 1999; 46: 817-821.

4 Leder SB, Espinosa JF. Aspiration risk after acute stroke: comparison of clinical examination and fiberoptic endoscopic evaluation of swallowing. Dysphagia 2002; 17: 214-218.

5 Mann G, Hankey GJ, Cameron D. Swallowing function after stroke: prognosis and prognostic factors at 6 months. Stroke 1999; 30: 744-748.

6 Caviedes IR, Lavados PM, Hoppe AJ, Lopez MA. Nasolaryngoscopic validation of a set of clinical predictors of aspiration in a critical care setting. J Bronchology Interv Pulmonol 2010; 17: 33-38.

7 Lim SH, Lieu PK, Phua SY, et al. Accuracy of bedside clinical methods compared with fiberoptic endoscopic examination of swallowing (FEES) in determining the risk of aspiration in acute stroke patients. Dysphagia 2001; 16: $1-6$.

8 Leder SB, Sasaki CT, Burrell MI. Fiberoptic endoscopic evaluation of dysphagia to identify silent aspiration. Dysphagia 1998; 13: 19-21.

9 DePippo KL, Holas MA, Reding MJ. Validation of the 3-oz water swallow test for aspiration following stroke. Arch Neurol 1992; 49: 1259-1261.

10 Zenner PM, Losinski DS, Mills RH. Using cervical auscultation in the clinical dysphagia examination in long-term care. Dysphagia 1995; 10: 27-31.

Copyright (CERS 2017

From the author:

We were very interested in the comments made by I. Cavedies and co-workers regarding our paper entitled "Oropharyngeal dysphagia: when swallowing disorders meet respiratory diseases" [1].

Nevertheless, regarding hemispheric stroke patients, it must be kept in mind that it is very difficult to predict oropharyngeal dysphagia with the location of the stroke because of the multiple cerebral locations involved in deglutition in health and disease [2]. For example, the dominant hemisphere for swallowing could not be predicted in healthy subjects [3], and it has been demonstrated that when this dominant hemisphere is affected by stroke, the patient should have post stroke dysphagia [4] and is a candidate for aspiration pneumonia [5]. In brainstem stroke, the dysphagia is very severe and those patients are often

Cite this article as: Verin E. Clinical screening of oropharyngeal dysphagia: standard of care. Eur Respir J 2017; 50: 1701447 [https://doi.org/10.1183/13993003.01447-2017]. 
candidates for gastrostomy. Treatment strategy is very poor, and we recently demonstrated that coupling rTMS and surgery could become an interesting option [6].

Because of the high prevalence of oropharyngeal dysphagia in stroke, it is very important to have a systematic attitude. Bedside screening is systematic, and different tests exist. The most often used is the three-ounce test, because it has a high sensitivity and specificity [7]. Nevertheless, it has some imperfections. The first one is not to detect silent aspirations, which are frequent; the second one is that it doesn't test different consistencies to adapt food; and the third one is that it has been validated only in stroke. That explains why the European Society of Swallowing Disorders (www.myessd.org) developed a new screening test based on viscosity and volume consistency [8]. Its advantages are detection of aspirations and silent aspirations with the use of an oximeter, and also detection of default in bolus propulsion in the pharynx. It has been validated against videofluoroscopy and in different populations, especially in old people [9] and in patients with amyotrophic lateral sclerosis [10].

\section{Eric Verin}

Rouen University Hospital, Rouen, France

Correspondence: Eric Verin, Rouen University Hospital - Pôle 3R, 1 rue de Germont, Rouen 76031, France.

E-mail: eric.verin@chu-rouen.fr

Received: July 182017 | Accepted: July 182017

Conflict of interest: None declared.

\section{References}

1 Verin E, Clavé P, Bonsignore MR, et al. Oropharyngeal dysphagia: when swallowing disorders meet respiratory diseases. Eur Respir J 2017; 49: 1602530.

2 Hamdy S, Aziz Q, Rothwell JC, et al. The cortical topography of human swallowing musculature in health and disease. Nat Med 1996; 2: 1217-1224.

3 Hamdy S, Rothwell JC, Aziz Q, et al. Organization and reorganization of human swallowing motor cortex: implications for recovery after stroke. Clin Sci (Lond) 2000; 99: 151-157.

4 Hamdy S, Aziz Q, Rothwell JC, et al. Recovery of swallowing after dysphagic stroke relates to functional reorganization in the intact motor cortex. Gastroenterology 1998; 115: 1104-1112.

5 Vilardell N, Rofes L, Nascimento WV, et al. Cough reflex attenuation and swallowing dysfunction in sub-acute post-stroke patients: prevalence, risk factors, and clinical outcome. Neurogastroenterol Motil 2017; 29.

6 Verin E, Leroi AM, Marie JP. Restoration of normal swallowing function in Wallenberg syndrome by repetitive transcranial magnetic stimulation and surgery. Ann Phys Rehabil Med 2016; 59: 343-345.

7 DePippo KL, Holas MA, Reding MJ. Validation of the 3-oz water swallow test for aspiration following stroke. Arch Neurol 1992; 49: 1259-1261.

8 Clavé P, Arreola V, Romea M, et al. Accuracy of the volume-viscosity swallow test for clinical screening of oropharyngeal dysphagia and aspiration. Clin Nutr 2008; 27: 806-815.

9 Serra-Prat M, Palomera M, Gomez C, et al. Oropharyngeal dysphagia as a risk factor for malnutrition and lower respiratory tract infection in independently living older persons: a population-based prospective study. Age Ageing 2012; 41: 376-381.

10 Paris G, Martinaud O, Hannequin D, et al. Clinical screening of oropharyngeal dysphagia in patients with ALS. Ann Phys Rehabil Med 2012; 55: 601-608. 